\title{
Uric Acid Abnormalities and Its Correlation with Splenectomy in Adult Transfusion Dependent Thalassemia Subjects (TDT)
}

\author{
Sahithi A ${ }^{1}$, Aggarwal R' ${ }^{*}$, Prakash A ${ }^{1}$, J ain SK', \\ Jain $\mathbf{A}^{2}$, Bansal $\mathbf{P}^{1}$ \\ ${ }^{1}$ Department of Medicine, Lady Hardinge Medical College \\ and Associated Hospitals, India \\ ${ }^{2}$ Department of Biochemistry, Lady Hardinge Medical \\ College and Associated Hospitals, India \\ *Corresponding author: Ramesh Aggarwal, \\ Department of medicine, Lady Hardinge Medical College \\ and Associated Hospitals, New Delhi, India
}

Received: March 09, 2021; Accepted: April 09, 2021; Published: April 16, 2021

\begin{abstract}
Background: In thalassemia patients erythrocyte turnover rate increases due to chronic hemolysis and ineffective erythropoiesis leading to increase in uric acid production. Hyperuricosuria is one of the marker of proximal tubular dysfunction. Splenectomy can increase the risk of hyperuricemia by increasing erythrocyte turnover rate in Transfusion Dependent Thalassemia (TDT). Deferasirox enhances uric acid excretion from renal tubules leading to low serum uric acid levels.
\end{abstract}

Methods: An institution based cross-sectional study was conducted from November 2018-March 2020 which included 60 adult TDT patients ( $\geq 18$ years) attending Adult Thalassemia Day Care Centre at tertiary care hospital. Serum uric acid (mg/dl), 24 hour urinary uric acid $(\mathrm{mg} / \mathrm{dl})$, serum ferritin $(\mathrm{ng} / \mathrm{ml})$ were done.

Results: Hyperuricemia was present in $20 \%$, hypouricemia in $3.33 \%$. Hyperuricosuria was present in $80 \%$. Mean SUA levels were higher in males than females which was statistically significant $(5.77 \pm 1.66$ vs $4.64 \pm 1.44, p=0.007)$. There was statistically significant positive correlation between serum uric acid and serum creatinine $(p=0.0036)$ and age $(p=0.0129)$. Hyperuricemia was more in subjects with intact spleen but was not statistically significant $(p=0.104)$. Hyperuricemia had negative association with deferasirox therapy [1 (3.03\%) vs $11(40.74 \%), p=0.0004]$ compared with normouricemia subjects.

Conclusion: Uric acid abnormalities were seen in $23.3 \%$ of patients. Hyperuricemia was present in one fourth of the patients and significant risk factors were increasing age, male gender, rising serum creatinine. Deferasirox therapy was negatively associated with hyperuricemia. Tubular dysfunction is relatively common in TDT as more than three fourth patients had hyperuricosuria. Regular monitoring of serum uric acid and urinary uric acid is recommended.

Keywords: Transfusion dependent thalassemia; Hyperuricemia; Hyperuricosuria; Splenectomy; Deferasirox

\section{Introduction}

Thalassemia is one of the most common inherited diseases worldwide which leads to chronic hemolytic anemia due to a partial or complete defect in the synthesis of $\alpha$ or $\beta$ globin chains. The prevalence of $\beta$-thalassemia in India is $3-4 \%$ and it is estimated that around 10,000-12,000 children were born every year with $\beta$-thalassemia major [1]. Thalassemia patients have enhanced erythrocyte turnover rate because of chronic haemolysis and ineffective erythropoiesis leading to increase in uric acid production. Therefore, hyperuricemia is anticipated. Uric acid has anti oxidant properties. Hyperuricemia is associated with increased risk of metabolic syndrome, iron overload, nephrolithiasis, renal dysfunction, gouty arthritis. In TDT patients proximal tubular dysfunction is common because of various reasons like chronic anemia, iron overload and chelation therapy. Proximal tubular dysfunction in TDT leads to hyperuricosuria due to the defective absorption of filtered uric acid, therefore hyperuricosuria is one of the marker of proximal tubular dysfunction [2-3]. However, there are scanty reports of uric acid abnormalities in TDT, especially adult subjects. Many patients undergo splenectomy to decrease transfusion requirement, to prevent growth retardation, symptomatic splenomegaly, leukopenia and thrombocytopenia. It has been observed that splenectomy can increase the risk of hyperuricemia by increasing erythrocyte turnover rate in thalasssemia patients [4]. Chelation therapy is an essential part of management of adult TDT. It has been observed that Deferasirox (DFX) enhances uric acid excretion from renal tubules leading to low serum uric acid levels [5]. Scanty data is available which highlights association of splenectomy and chelating agents with uric acid abnormalities. This study is an attempt to bridge the existing lacunae in knowledge with regard to uric acid abnormalities in adult TDT.

\section{Materials and Methods}

Our study was a descriptive cross-sectional study and included 60 adult TDT patients confirmed by High Performance Liquid Chromatography (HPLC) of age $\geq 18$ years attending Adult
Ann Hematol Oncol - Volume 8 Issue 5 - 2021

Aggarwal et al. () All rights are reserved
Citation: Sahithi A, Aggarwal R, Prakash A, Jain SK, Jain A, Bansal P. Uric Acid Abnormalities and Its Correlation with Splenectomy in Adult Transfusion Dependent Thalassemia Subjects (TDT). Ann Hematol Oncol. 2021; 8(5): 1342. 
Thalassemia Day Care Centre (TDCC) at tertiary care hospital. Subjects who were on medications affecting uric acid metabolism were excluded from the study. The study was approved by institutional research committee and ethical committee. The detailed clinical history was taken which included demographic data, dietary history, number of blood transfusions they receive every month, chelation therapy (dosage and duration of drug therapy), history of splenectomy, history of any other medications and menstrual history in females. General physical examination which include height, weight, body mass index (BMI) and systemic examination was done in all subjects.

\section{Biochemical investigations}

Serum Uric Acid (SUA), 24-hour Urinary Uric Acid (UUA), serum ferritin $(\mathrm{ng} / \mathrm{ml})$ and routine blood investigations were done. SUA and UUA were analysed by colorimetric method which uses uricase enzyme converting uric acid to allantoin and hydrogen peroxide. Hyperuricemia was defined as SUA of $>7.0 \mathrm{mg} / \mathrm{dL}$ for men and $>5.7 \mathrm{mg} / \mathrm{dL}$ for women and hypouricemia was defined as SUA $<2$ $\mathrm{mg} / \mathrm{dl}$ [6]. Hyperuricosuria was defined as 24 hour UUA>750 mg/ day while on a normal, unrestricted purine diet $[7,8]$. The Estimated Glomerular Filtration Rate (eGFR) was calculated using the following formula Cockcroft-Gault formula $((140-$ age $) \times$ weight in $\mathrm{kgs} /$ (72×serum creatinine) $\times 0.85$ (if female) $)$ [9]. Renal hyperfiltration was defined as eGFR $>135 \mathrm{ml} / \mathrm{min} / \mathrm{m}^{2}$ [10].

\section{Statistical analysis}

Categorical variables were presented in number and percentage (\%) and continuous variables as mean \pm SD and median. Normality of data was tested by Kolmogorov-Smirnov test. If the normality was rejected then non parametric test was used. Quantitative variables were compared using independent $t$ test/Mann-Whitney Test (as the data sets were not normally distributed) between the two groups and ANOVA test between more than two groups. Qualitative variables were correlated using Chi-Square test/Fisher's test. Pearson correlation coefficient/Spearman rank correlation coefficient was used to assess the correlation of various parameters with SUA, $24 \mathrm{hr}$ UUA. A p value of $<0.05$ was considered statistically significant. The data was entered in MS EXCEL spreadsheet and analysis was done.

\section{Results}

Our study comprised of 60 adult TDT subjects with mean age of $23.10 \pm 4.55$ years (18-38). Majority of the subjects were in the age group of $21-30$ years (58.33\%). In our study males were $58.33 \%$ $(n=35)$ and females were $41.66 \%(n=25)$ (Table 1$)$.

Hyperuricemia was present in $20 \%(\mathrm{n}=12)$ and hypouricemia in $3.33 \%(\mathrm{n}=2)$ of subjects, mean SUA was $5.30 \pm 1.66 \mathrm{mg} / \mathrm{dl}$ and total uric acid abnormalities were present in $23.33 \%(\mathrm{n}=14)$. Hyperuricemia was seen in $8.33 \%(n=5)$ of females and $11.66 \%(n=7)$ of males. Mean value of SUA increased proportionately as the age of the subjects increased which was statistically significant $(\mathrm{p}=0.0129)$. Mean SUA levels were higher in males than females and the difference was statistically significant $(5.77 \pm 1.66$ vs $4.64 \pm 1.44, \mathrm{p}=0.007)$.

Hyperuricosuria was present in $80 \%(\mathrm{n}=48)$ and hyperfiltration was found in $66.67 \%(n=32)$ of subjects. Mean value of $24 \mathrm{hr}$ UUA was $1535.38 \pm 1017.45 \mathrm{mg} / \mathrm{dl}$. In our study there was a statistically significant positive correlation between SUA and serum creatinine
Table 1: Demographic data of adult TDT subjects.

\begin{tabular}{|l|c|}
\hline \multicolumn{1}{|c|}{ Characteristics } & Mean \pm SD (n=60) \\
\hline Age (years) & $23.10 \pm 4.6$ \\
\hline Male & $35(58.33 \%)$ \\
\hline Females & $25(41.66 \%)$ \\
\hline Height (cm) & $154.03 \pm 9.1$ \\
\hline Weight (kilogram) & $48.83 \pm 8.23$ \\
\hline BMI (kg/m²) & $20.58 \pm 3.05$ \\
\hline Serum uric acid (mg/dl) & $5.30 \pm 1.66$ \\
\hline 24 hours UUA (mg/dl) & $1535.38 \pm 1017.45$ \\
\hline Serum ferritin (ng/ml) & $2634.84 \pm 1761$ \\
\hline Blood urea (mg/dl) & $25.18 \pm 7.28$ \\
\hline Serum creatinine (mg/dl) & $0.61 \pm 0.15$ \\
\hline eGFR (ml/min/1.73m²) & $161.5 \pm 41.45$ \\
\hline Haemoglobin (g/dl) & $8.72 \pm 0.82$ \\
\hline Chelating therapy & $60(100 \%)$ \\
\hline Deferasirox (DFX) monotherapy & $13(21.67 \%)$ \\
\hline Deferiprone (DFP) monotherapy & $17(28.33 \%)$ \\
\hline Deferioxamine (DFO) monotherapy & $2(3.33 \%)$ \\
\hline DFX and DFP combination & $5(8.33 \%)$ \\
\hline DFX and DFO combination & $5(8.33 \%)$ \\
\hline DFP and DFO combination & \\
\hline DFX, DFP and DFO & $16.67 \%)$ \\
\hline
\end{tabular}

Table 2: Correlation of SUA with different variables.

\begin{tabular}{|c|c|c|}
\hline \multicolumn{2}{|c|}{ Correlation matrix } & Serum uric acid $(\mathrm{mg} / \mathrm{dl})$ \\
\hline \multirow{3}{*}{ Age in years } & Correlation Coefficient & 0.319 \\
\cline { 2 - 3 } & $\mathrm{p}$ value & 0.0129 \\
\cline { 2 - 3 } & $\mathrm{n}$ & 60 \\
\hline \multirow{2}{*}{ Serum creatinine $(\mathrm{mg} / \mathrm{dl})$} & Correlation Coefficient & 0.37 \\
\cline { 2 - 3 } & $\mathrm{p}$ value & 0.0036 \\
\cline { 2 - 3 } & $\mathrm{n}$ & 60 \\
\hline \multirow{2}{*}{ Serum ferritin $(\mathrm{ng} / \mathrm{ml})$} & $\mathrm{p}$ value & -0.171 \\
\cline { 2 - 3 } & $\mathrm{n}$ & 0.191 \\
\hline & & 60 \\
\hline
\end{tabular}

Table 3: Association of SUA with different variables.

\begin{tabular}{|c|c|c|c|c|}
\hline Characteristics & Hyperuricemia & Hypouricemia & Normouricemia & $P$ value \\
\hline $\begin{array}{l}\text { Intact spleen } \\
\quad(n=48)\end{array}$ & $12(25 \%)$ & $2(4.17 \%)$ & $34(70.83 \%)$ & \multirow{2}{*}{0.104} \\
\hline $\begin{array}{l}\text { Splenectomised } \\
(\mathrm{n}=12)\end{array}$ & $0 \%$ & $0 \%$ & $12(100 \%)$ & \\
\hline $\begin{array}{l}\text { Deferasirox } \\
(n=33)\end{array}$ & $1(3.03 \%)$ & $2(6.06 \%)$ & $30(90.91 \%)$ & \multirow{2}{*}{0.0004} \\
\hline $\begin{array}{l}\text { Non deferasirox } \\
\quad(n=27)\end{array}$ & $11(40.74 \%)$ & $0 \%$ & $16(59.26 \%)$ & \\
\hline
\end{tabular}

$(\mathrm{p}=0.0036)$ (Table 2). Mean value of serum creatinine was $0.61 \pm 0.15$ $\mathrm{mg} / \mathrm{dl}$ and eGFR was $161.5 \pm 41.45 \mathrm{ml} / \mathrm{min} / 1.73 \mathrm{~m}^{2}$. There was no statistically significant correlation between 24 hour UUA and eGFR $(\mathrm{p}=0.533)$ and serum creatinine $(\mathrm{p}=0.869)$.

In our study splenectomy was done in $20 \%(\mathrm{n}=12)$ of subjects. 
Proportion of hyperuricemia was more in subjects with intact spleen than splenectomy, but was not statistically significant $(25 \%$ vs $0 \%$, $\mathrm{p}=0.104$ ) (Table 3). Hyperuricemia was found to have negative association with deferasirox therapy $[1$ (3.03\%) vs 11 (40.74\%), $\mathrm{p}=0.0004]$ compared with normouricemia subjects. There was no statistically significant correlation of SUA with serum ferritin $(\mathrm{p}=0.191)$ (Table 2).

\section{Discussion}

Our study comprised of 60 transfusion dependent adult thalassemia subjects with mean age of $23.10 \pm 4.55$ years (18-38). Majority of the subjects were in the age group of 21-30 years (58.33\%). Chaloemwong et al. [11] studied 58 thalassemia patients with mean age of 23.5 years (16-41).

In our study, proportion of hyperuricemia was $20 \%(\mathrm{n}=12)$ and hypouricemia was $3.33 \%(\mathrm{n}=2)$. In a study done by Vassalle et al. [12] on $369 \beta$-thalassemia major patients with mean age of $33 \pm 6$ years reported that proportion of hyperuricemia was $5 \% \quad(n=19)$ and mean SUA was $4.4 \pm 1.2 \mathrm{mg} / \mathrm{dl}$. In a prospective study done by Hamed et al. [13] on 69 thalassemia major patients of age 1-16 years and 15 age and sex matched controls were taken, reported that SUA levels were increased in thalassemic subjects when compared to controls $(\mathrm{p}<0.002)$. Doddamani et al. [14] studied on 30 thalassemia major subjects with age group of 6 months-14 years and compared with 30 age and sex matched controls elucidated that SUA levels were significantly increased in $\beta$ thalassemia major patients when compared to controls $(\mathrm{p}<0.05)$. Hypouricemia was seen in $2.33 \%$ $(n=2)$ of subjects and both had hyperuricosuria. Cetin et al. [15] studied 41 thalassemia minor subjects with age group 19-40 years and compared with 20 age and sex matched controls reported that $14.6 \%$ $(n=6)$ of subjects had hypouricemia because of increased fractional excretion of uric acid. The difference in proportion of hypouricemia could be because of the difference in study population included in their study, that is thalassemia minor. Mean SUA levels were higher in males than females and the difference was statistically significant ( $5.77 \pm 1.66$ vs $4.64 \pm 1.44, \mathrm{p}=0.007)$. In a study done by Vassalle et al. [12] on $369 \beta$-thalassemia major patients with mean age of $33 \pm 6$ years found that mean serum uric acid levels were significantly higher in male than in female patients $(4.8 \pm 1.3 v s 4.0 \pm 1.0 \mathrm{mg} / \mathrm{dl} ; \mathrm{p}<0.001)$. Our study observed that mean value of SUA increased proportionately as the age of the subjects increased which was statistically significant ( $\mathrm{p}=0.0129$ ). Chaloemwong et al. [11] studied 58 thalassemia patients with mean age of 23.5 years observed that increasing age was a significant risk factor for hyperuricemia $(\mathrm{p}=0.046)$.

Hyperuricosuria was found in $80 \%(n=48)$ in our study and it is one of the marker of proximal tubular dysfunction. Similar results were found in study done by Smolkin et al. [16] on 37 thalassemia major subjects where hyperuricosuria was present in $82.4 \%$. Study done by Ahmadzadeh et al. [17] reported that hyperuricosuria is a marker of proximal tubular dysfunction was found in $58.6 \%$ of patients. Renal hyperfiltration (eGFR $\geq 135 \mathrm{ml} / \mathrm{min} / \mathrm{m}^{2}$ ) in TDT can occur because of chronic hypoxia or chronic anemia leading to hyperdynamic circulation resulting in increase in renal plasma flow and decrease in glomerular vascular resistance [18]. In our study hyperfiltration was present in $66.67 \%(n=32)$. In a study done by Deveci et al. [19] on 84 thalassemia major and 12 Thalassemia Intermedia (TI) patients reported renal hyperfiltration in $40 \%$ of patients.

We observed that proportion of hyperuricemia was more in subjects with intact spleen than splenectomised subjects, however, the difference was not statistically significant $(\mathrm{p}=0.104)$. In a cross sectional study done by Chaloemwong et al. [20] on 112 thalassemic patients and proportion of splenectomised patients was high $59.8 \%(n=67)$. They observed that intact spleen was a risk factor for hyperuricemia $(\mathrm{p}=0.01)$. In a retrospective study done by Ricchi et al [4] on 89 TI patients and splenectomy was done in $48 \%$ of subjects. They found that splenectomy was a risk factor for hyperuricemia. The difference in the observations could be accounted for low proportion of splenectomy in our study which may be due to difference in the protocols for splenectomy in different centres. There was a statistically significant positive correlation between SUA and serum creatinine $(\mathrm{p}=0.0036)$. Similar observations was done by Chaloemwong et al. [11] on 58 thalassemia patients with mean age of 23.5 years observed that hyperuricemic patients had higher mean serum creatinine $(\mathrm{p}=0.03)$ and lower fractional excretion of uric acid than thalassemia patients who had normal uric acid level.

Hyperuricemia was found to have negative association with DFX therapy ( $\mathrm{p}=0.0004)$ compared with normouricemia subjects. Chaloemwong et al. [19] studied 112 thalassemic patients with mean age of 29 years reported that subjects who were on DFX therapy had lower serum uric acid levels which is due to increase in excretion of uric acid from renal tubules leading to low serum uric acid levels. Vlachaki et al. [5] studied 53 beta thalassemia major subjects with mean age $22.4 \pm 14.7$ years. They found statistically significant difference between the mean values of SUA before and after the start of DFX therapy and reported that DFX augments the excretion of uric acid from renal tubules. They concluded that uric acid can be used as predictor factor of response to DFX therapy.

In our study, there was no statistically significant correlation between SUA and serum ferritin levels $(\mathrm{p}=0.191)$. This is in concordance with the study done by Vassalle et al. [12] on 369 $\beta$-thalassemia major patients with mean age of $33 \pm 6$ years found that serum uric acid levels didn't have statistically significant correlation with serum ferritin levels.

\section{Conclusion}

Uric acid abnormalities were seen in $23.3 \%$ of patients. Hyperuricemia was present in one fourth of the patients and significant risk factors were increasing age, male gender, rising serum creatinine. Deferasirox therapy was negatively associated with hyperuricemia. Tubular dysfunction is relatively common in TDT as more than three fourth patients had hyperuricosuria. Regular monitoring of serum uric acid and urinary uric acid is recommended.

\section{Author's Contributions}

All authors contributed to the study conception and design. Material preparation, data collection and analysis were performed by Dr Avva Sahithi, Dr Ramesh Aggarwal, Dr Anupam prakash, Dr S.K. Jain, Dr Anju jain and Dr Priya Bansal. The first draft of the manuscript was written by Dr Avva Sahithi and all authors commented on previous versions of the manuscript. All authors read and approved the final manuscript. 


\section{References}

1. Mohanty D, Colah RB, Gorakshakar AC, et al. Prevalence of $\beta$-thalassemia and other haemoglobinopathies in six cities in India: A multicentre study. J Community Genet. 2013; 4: 33-42.

2. Hamed EA, Elmelegy NT. Renal functions in pediatric patients with beta thalassemia major: relation to chelation therapy: original prospective study. Ital J Pediatr. 2010; 36: 39.

3. Aldudak B, Karabay Bayazit A, Noyan A, Ozel A, Anarat A, Sasmaz I, et al. Renal function in pediatric patients with beta thalassemia major. Pediatr Nephrol. 2000; 15: 109-112.

4. Ricchi $P$, Ammirabile $M$, Costantini $S$, et al. Splenectomy is a risk factor for developing hyperuricemia and nephrolithiasis in patients with thalassemia intermedia: a retrospective study. Blood Cells Mol Dis. 2012; 49: 133-135.

5. Vlachaki E, Perifanis V, kondou A, Neokleous N, Teli A, Oikonomou M Serum uric acid as a predictor factor of the response to deferasirox therapy for patients with b-thalassemia major. Blood. 2011; 118: 5306.

6. Mecchella JN, Burns CM. Disorders of Purine and Pyrimidine metabolism Editors. In: Kasper DL, Fauci AS, Jameson JL, et al. Harrison's Principles of Internal Medicine, $20^{\text {th }}$ edition. 2018: 2997-3000.

7. Perez-Ruiz F, Calabozo M, Erauskin GG, Ruibal A, Herrero-Beites AM. Renal underexcretion of uric acid is present in patients with apparent high urinary uric acid output. Arthritis Rheum. 2002; 47: 610-613.

8. Emmerson BT. The Management of Gout. N Engl J Med. 1996; 334: 445-451.

9. Kidney Disease: Improving Global Outcomes KDIGO. Clinical practice guideline for the evaluation and Management of Chronic Kidney Disease (2013). Off J Int Soc Nephrol. 2012; 3.

10. Cachat F, Combescure C, Cauderay M, Girardin E, Chehade H. A systematic review of glomerular hyperfiltration assessment and definition in the medical literature. Clin J Am Soc Nephrol. 2015; 10: 382-389.

11. Chaloemwong J, Tantiworawit A, Louthrenoo W. Hyperuricemia and Musculoskeletal Complications in Thalassemia patients. Blood. 2017; 130: 4761.
12. Vassalle C, Meloni A, Pistoia L, Gamberini MR, Spasiano A, Gerardi C, et al. Relationship between uric acid levels and cardiometabolic findings in a large cohort of $\beta$-thalassemia major patients. Biomark Med. 2018; 12: 341-348.

13. Hamed EA, Elmelegy NT. Renal functions in pediatric patients with beta thalassemia major: relation to chelation therapy: original prospective study. Ital J Pediatr. 2010; 36: 39

14. Doddamani $P$, Suma $M N$, Ravi MD, Prashant $A$, Vishwanath $P$, Nagalakshmi CS. Importance of assessment of microalbuminuria in $\beta$-thalassemia major patients. Int J Health Allied Sci. 2012; 1: 235-238.

15. Cetin T, Oktenli C, Ozgurtas T, Yenicesu M, Sanisoglu SY, Oguz Y, et al. Renal tubular dysfunction in beta-thalassemia minor. Am J kidney Dis. 2003; 42: 1164-1168.

16. Smolkin V, Halevy R, Levin C, Mines M, Sakran W, Llia K, et al. Renal function in children with beta-thalassemia major and thalassemia intermedia. Pediatr Nephrol. 2008; 23: 1847-1851.

17. Ahmadzadeh A, Jalali A, Assar S, Khalilian H, Zandian K, Pedram M. Renal tubular dysfunction in pediatric patients with beta-thalassemia major. Saudi J Kidney Dis Transpl. 2011; 22: 497-500.

18. Helal I, Fick-Brosnahan GM, Reed-Gitomer B, Schrier RW. Glomerular hyperfiltration: definitions, mechanisms and clinical implications. Nat Rev Nephrol. 2012; 8: 293-300.

19. Deveci B, Kurtoglu A, Kurtoglu E, Salim O, Toptas T. Documentation of renal glomerular and tubular impairment and glomerular hyperfiltration in multitransfused patients with beta thalassemia. Ann Hematol. 2016; 95: 375381.

20. Chaloemwong J, Tantiworawit A, Rattanathammethee T, Chai-Adisaksopha C, Rattarittamrong E, Norasetthada L, et al. Hyperuricemia, urine uric excretion, and associated complications in thalassemia patients. Ann Hematol. 2019; 98: 1101-1110. 